LIAMES 1 - pp. 75-87, Primavera 2001

Fábio Bonfin Duarte
(UFJF/PG-UFMG)

\title{
Construções de Gerúndio na Língua Tembé
}

\begin{abstract}
:
The purpose of this paper is to present the results of research on Tembé, a Tupi-Guarani language of Northeast of Brazil, with special focus on the cross-referencing system of the gerund constructions. The analysis of the data showed that the subject $(\mathrm{Sa})$ of the intransitive verbs can be identical to either the subject or the object of the preceding clause, whereas the subject (A) of the transitive verbs and (So) of the descriptive verbs can only be identical to the subject of the main clause.

The gerund constructions also exhibits a split system: one in which the cross-referencing of So and $\mathrm{O}$ is done by the relational prefixes, comprising an ergative system, and another in which the cross-referencing of $\mathrm{A}$ is done by the nominative prefixes. In this system, the A function is not cross-referenced.
\end{abstract}

\section{INTRODUÇÃO}

O objetivo desse artigo é apresentar o sistema de codificação dos argumentos A, Sa, So e O nas orações de gerúndio na Língua Tembé e verificar se este sistema coincide com o existente em outras línguas da família Tupí-Guaraní, em especial a Língua Tupinambá e a Língua Guajajara. Além da codificação dos argumentos, investigam-se, também, as condições sintáticas de correferência do sujeito com o sujeito da oração principal.

Os índios Tembé partilham praticamente a mesma língua e tradição cultural com os Guajajara e consideram-se com estes, um só povo, autodenominando-se Tenetehara, o que significa "a gente, os índios em geral e mais especialmente os índios Tembé e Guajajara" (Boudin: 1966:258). Os Tembé migraram da região do rio Pindaré em direção aos rios Gurupi, Capim e Guamá, onde habitam atualmente. A língua Tembé está incluída na família lingüística Tupí-Guaraní. Segundo a classificação de Rodrigues (1984/1985:39), ela pertence ao subconjunto IV e compartilha traços fonológicos e de estrutura com o Tapirapé, o Avá-Canoeiro, o Assurini do Tocantins (Akuáwa), o Parakanã e o Guajajara.

A língua Tembé é falada atualmente sobretudo pelos índios do rio Gurupí, já que grande parte dos índios do rio Guamá praticamente não fala mais a língua. A situação lingüística dos índios do Gurupí, entretanto, é de multilingüismo em decorrência do contato 
com a sociedade nacional e com o povo Ka'apor, cuja língua muitos Tembé falam, além da própria e da portuguesa. Das seis aldeias atuais, apenas uma preserva a língua como veículo diário de comunicação, nas outras cinco, com exceção dos mais velhos, usa-se muito freqüentemente o português. Por isso, tem havido esforços por parte das lideranças indígenas locais no sentido de estimular o ensino da língua nativa. Algumas iniciativas neste sentido têm sido tomadas recentemente com a formação de professores indígenas para o trabalho de alfabetização tanto de adultos quanto de crianças e com o envio de índios mais velhos para outras aldeias para ensinar os mais jovens.

\section{CONSIDERAÇÕES SOBRE A PARTÍCULA Pə}

Em geral, identificam-se as orações de gerúndio pela ocorrência da partícula $p \curvearrowright$, que sempre vem posposta ao verbo da oração [[OV] pə]. Segundo Rodrigues, em comunicação pessoal, há indícios de que a língua Tembé também indicava o gerúndio por meio de um sufixo verbal tal como no Tupinambá,. Por razões diacrônicas, este transformou-se na atual partícula $p$.

Esta hipótese se fundamenta no fato de que, no Tupinambá, o verbo da oração de gerúndio recebia o sufixo - $a$ ßo que tinha as seguintes variações morfofonêmicas:

(a) após vogal alta $\left(\mathrm{V}^{\text {alta }}\right) / \ldots$, o sufixo tomava a forma $-a \beta o$;

(b) após vogal baixa $\left(\mathrm{V}^{\text {baixa }}\right) / \ldots$, o sufixo tomava a forma $-\beta o$;

(c) após consoantes (C) /_, ele tomava a forma $-a$;

(d) precedida por consoante bilabial fricativa, esta transformava-se em oclusiva surda homorgânica: $(-\beta>p)-a$

A hipótese sugerida é que a partícula pə do Tembé deve ter-se originado a partir da situação descrita em (d).

\section{CARACTERÍSTICAS GERAIS}

As orações subordinadas de gerúndio correspondem aproximadamente ao que as gramáticas tradicionais do português classificam como sendo orações reduzidas de gerúndio e de infinitivo. Elas podem exprimir 'um processo realizado simultaneamente com outro processo (gerúndio contemporâneo)', 'a finalidade ou propósito do processo indicado por outro verbo (gerúndio final)' e 'um processo realizado pelo mesmo sujeito que já realizou outro processo, mas sem simultaneidade (gerúndio aditivo)' (Rodrigues, 1953:126).

As relações sintáticas, nestas orações, são orientadas para referir-se ao sujeito ou ao objeto, dependendo do tipo de construção sintática na qual o verbo e seus argumentos ocorrem. Nas construções transitivas, codifica-se o objeto e nas intransitivas o sujeito. A referência a estes argumentos está relacionada a fatores tais como:

(i) a contigüidade, ou não, do objeto $(\mathrm{O})$ em relação ao verbo transitivo e do sujeito (So) em relação ao verbo descritivo;

(ii) os prefixos nominativos que ocorrem nos verbos intransitivos para codificar Sa. 
Esses fatores determinarão, como veremos adiante, um sistema de marcação de caso cindido: em parte, ergativo, em parte, nominativo. Averigüemos inicialmente como o sistema ergativo se realiza nas orações de gerúndio com verbos transitivos.

\section{CONSTRUÇÕES TRANSITIVAS}

Os verbos transitivos fazem referência somente ao sintagma nominal na função sintática de objeto. O sintagma nominal na função de sujeito (A) é, em geral, correferente com o sujeito (A) ou (Sa) da oração principal. Os marcadores verbais que ocorrem para codificar o objeto estão associados aos seguintes fatores:

(i) a classe temática à qual pertence o verbo;

(ii) a posição de $\mathrm{O}$ em relação ao verbo transitivo da oração de gerúndio.

\subsection{Objeto contíguo ao verbo}

Os predicados que têm o objeto contíguo ao verbo designam esta relação através do prefixo relacional $\{\varnothing-\sim$ r- $\}$. Os exemplos (1), (2), (3) e (4) ilustram a ocorrência deste prefixo nas duas classes de temas verbais transitivos.

\section{$\underline{\text { Temas verbais da classe I }}$}

(1) Gerúndio final

\begin{tabular}{|c|c|c|c|}
\hline upaw & $\begin{array}{l}\text { kwehe } \\
\text { PASS }\end{array}$ & $\begin{array}{l}\text { oro-ho } \\
13 \text {-ir }\end{array}$ & $\begin{array}{l}a^{\prime} e \\
\text { esse }\end{array}$ \\
\hline pira & $\varnothing-p \dot{z} h \dot{i} k$ & pə & \\
\hline peixe & REL-pegar & GE & \\
\hline
\end{tabular}

'Nós todos fomos nesse dia para pegar peixe'

(2) Gerúndio Contemporâneo

$\begin{array}{llll}i \text {-katu } & \text { ru'u } & d a-i k o & \text { nadewe } \\ \text { 3-bom } & \text { DUB } & 12 \text {-estar } & \text { assim } \\ \text { dane } & \varnothing \text {-de'eワ } & \varnothing \text {-mu-kiddim } & \text { pə? } \\ 12 & \text { REL-fala } & \text { REL-CAUS-perder-se } & \text { GER }\end{array}$

'Será bom nós estarmos perdendo a nossa língua assim?'

Temas verbais da classe II

(3) Gerúndio final

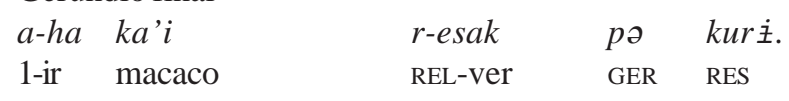

'Eu fui para ver o macaco então' 
(4) Gerúndio contemporâneo

\begin{tabular}{|c|c|}
\hline$o-m$ & \\
\hline -colocar & mandioca \\
\hline
\end{tabular}

'A gente coloca jogando a mandioca'

Vê-se, nos exemplos acima, que os alomorfes do prefixo relacional $\{\varnothing-\sim \mathrm{r}-\}$ alternam-se, quando o objeto está contíguo ao verbo. Os temas verbais da classe I - $p \dot{z} h \dot{i} k$ 'pegar' e -mukid $\dot{\text { im }}$ 'perder' recebem o alomorfe $/ \varnothing-/$, que faz referência aos sintagmas pira $\mathrm{e}$

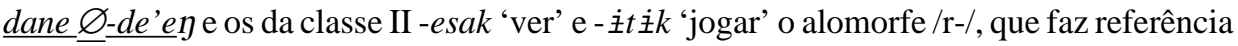
aos sintagmas ka'i e mani'ok.

$\mathrm{Na}$ Língua Guajajara, assim como na língua Tembé, codifica-se $\mathrm{O}$ por meio do prefixo relacional de contigüidade $\{\varnothing-\sim \mathrm{r}-\}$, como no exemplo (5), retirado de Bendor-Samuel (1972:141). Neste exemplo, o tema verbal transitivo -ika 'quebrar' pertence à classe I.

(5) Gerúndio final

$$
\begin{array}{llll}
o-h o & \text { wohu } & \varnothing \text {-ika } & p ə \\
\text { 3-ir côco } & \text { REL-quebrar } & \text { GER } \\
\text { 'Ele foi para quebrar côco' }
\end{array}
$$

Dados retirados de Rodrigues (1953:130), também confirmam a existência do mesmo tipo de referência na Língua Tupinambá. Os seguintes exemplos, ambos com o gerúndio final, apresentam temas verbais da classes I e II. Neles, a referência a $\mathrm{O}$ se faz por meio do prefixo relacional $\{\varnothing-\sim \mathrm{r}-\}$.

\section{$\underline{\text { Tema verbal da classe I }}$}

(6) Gerúndio final

o-úr kunumi $\quad \varnothing$-kuáp-a

3-vir menino REL-conhecer-GER

'Veio para conhecer o menino'

\section{Tema verbal da classe II}

(7) Gerúndio final

$\begin{array}{ll}\text { o-úr kunumi } & r \text {-epják-a } \\ \text { 3-vir menino } & \text { REL-ver-GER } \\ \text { 'Veio para ver o menino' } & \end{array}$

\subsection{Objeto não contíguo}

Outros contextos há em que o objeto, seja porque foi omitido por razões discursivas, como nos exemplos (8) e (10), seja porque foi mencionado anteriormente na sentença, como nos exemplos (9) e (11), não ocorre em posição sintática contígua ao verbo. Nesses casos, o prefixo relacional $\{\mathrm{i}-\sim \mathrm{h}-\}$ de não contigüidade é o que ocorre. 
Duarte: Construções de Gerúndio na Língua Tembé

Tema verbal da Classe I

(8)

Gerúndio final

\begin{tabular}{|c|c|c|c|c|}
\hline upaw & kwehe & oro-ho & $a^{\prime} e$ & mehe \\
\hline todos & PASS & 13-ir & esse & quando \\
\hline$i-p \dot{z} h \dot{i} k$ & pə. & & & \\
\hline REL-pegar & GER. & & & \\
\hline
\end{tabular}

(9)

$\begin{array}{llll}\text { u-pìhik tre pira } & \text { o-mono } & \text { dapepo } & \text { pupe } \\ \text { 3-pegar três peixes } & \text { 3-coloca } & \text { panela } & \text { dentro de } \\ \text { i-mimud } & \text { pə. } & & \\ \text { REL-cozinhar } & \text { GER } \\ \text { 'A gente pega três peixes e coloca dentro da panela para cozinhá-los' }\end{array}$

\section{Tema verbal da classe II}

Gerúndio final

aha h-esak po kuri.

1-ir REL-ver GER RES

'Eu fui para vê-lo (= o macaco) então'

Gerúndio aditivo

(11) $u$-p主hik pira tete-a'u teko

3-pegar peixe muito-INT a gente

h-erur po kurí.

REL-trazer GER RES

'A gente pega muito peixe e os traz agora'

Em (8) e (10), os prefixos relacionais $\{\mathrm{i}-\sim \mathrm{h}-\}$ referem-se, respectivamente, aos sintagmas pira 'peixe' e ka'i 'macacos', que foram omitidos das sentenças (1) e (3). Em (9) e (11), os SNs tre pira 'três peixes' e pira 'peixe', mencionados nas orações anteriores [u-p $\dot{\dot{x}} h \dot{\mathrm{i}} k$ tre pira] e [u-p $\dot{\text { i }}$ i $k$ pira tete- $a$ 'u teko], são referidos, na oração de gerúndio, pelos mesmos prefixos.

Como veremos na próxima seção, a estratégia de codificação de $\mathrm{O}$, nas orações acima, partilha semelhanças com a usada para a codificação de So dos verbos descritivos. Ambas as estratégias têm, em comum, o fato de usarem os prefixos relacionais e subordinarem-se ao critério de contigüidade. Comparando os dados do Guajajara e do Tupinambá com os do Tembé acima, verifica-se que as três línguas apresentam o mesmo tipo de codificação para os contextos de não contigüidade de $\mathrm{O}$.

O exemplo (12) da língua Guajajara (Bendor-Samuel, 1972:143) e os exemplos (13) e (14) da língua Tupinambá (Rodrigues, 1953:130) confirmam esta semelhança. A codificação de $\mathrm{O}$, nestas línguas, é realizada por meio dos mesmos marcadores. Na Língua Guajajara, eles tomam a mesma forma que na da língua Tembé $\{\mathrm{i}-\sim$ h- $\}$, e, na língua Tupinambá, eles tomam a forma $\{\mathrm{i}-\sim \mathrm{s}-\}$. 


\section{Tema verbal da classe II}

Gerúndio final (exemplo da língua Guajajara)

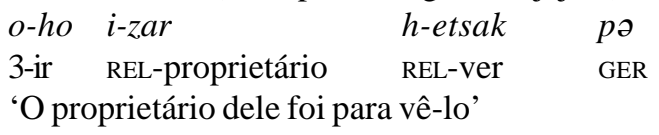

\section{Tema verbal da classe I}

Gerúndio final (exemplo da língua Tupinambá)

(13) o-úr i-kuap-a

3-vir REL -conhecer-GER

'Veio para conhecê-lo'

\section{Tema verbal da classe II}

Gerúndio final (exemplo da língua Tupinambá)

(14) o-úr s-epják-a

3-vir REL-ver-GER

'Veio para vê-lo'

Conclui-se, portanto, pela apresentação feita nas duas seções anteriores, que o sistema de codificação de $\mathrm{O}$ nas orações de gerúndio na língua Tembé preserva as mesmas características sintáticas básicas que as da língua Tupinambá e da língua Guajajara, tal como descrito em Rodrigues (1953) e Bendor-Samuel (1972).

Além da semelhança na codificação de $\mathrm{O}$, observa-se ainda que, nas orações de gerúndio com verbo transitivo, exemplos (1) a (14), o sujeito é sempre correferente com o da oração principal, seja ele A ou Sa.

\section{CONSTRUÇÕES COM VERBOS DESCRITIVOS}

Os verbos descritivos expressam, em geral, conceitos referentes a cores, tamanho, aparência, estados da mente, forma, largura, etc., e equivalem ao que a gramática relacional define como verbos inacusativos (cf. Pontes, 1986:79-80).

A estratégia de codificação do sujeito So nos verbos descritivos é muito semelhante à de $\mathrm{O}$ nos verbos transitivos, já que ambas estratégias utilizam os mesmos marcadores, os prefixos relacionais. Nos exemplos (15) a (17), a codificação é realizada pela ocorrência, no tema verbal -uríwete, do alomorfe/r-/ para marcar a contigüidade de So. Em (15) e (16), So é representado pelos pronomes: he 'eu' e ne 'você', e, em (17), pelo sintagma nominal Siba . 


\section{Temas da classe I}

(15) Gerúndio final

$$
\begin{array}{llll}
a-h a & \text { he } & \text { r-uriwete } & p ə . \\
\text { 1-ir } 1 & \text { REL-alegre } & \text { GER } \\
\text { 'Eu fui para eu ficar alegre, } &
\end{array}
$$

(16) Gerúndio final

$$
\begin{array}{llll}
r e-h o & \text { ne } & \text { r-uriwete } & \text { pə. } \\
\text { 2-ir } 2 & \text { REL-alegre GER } \\
\text { 'Você foi para vocêficar alegre' }
\end{array}
$$

(17) Gerúndio final

$$
\begin{array}{lll}
a-h a & \underline{\text { Siba }} & \text { r-uriwete } \\
\text { 1-ir } & \text { Siba } & \text { REL-alegre GER } \\
\text { 'Eu fui para Siba ficar alegre' }
\end{array}
$$

Entretanto, se omitirmos o sintagma nominal Siba, em (17), produziremos a sentença (18), ilustrativa das situações sintáticas nas quais o argumento So não vem contíguo ao tema verbal descritivo. Neste caso, substitui-se o alomorfe do prefixo de contigüidade /r-/ pelo de não contigüidade $/ \mathrm{h}-/$.

\section{Tema da Classe II}

(18) $\quad a$-ha h-uriwete po

1-ir REL-alegre GER

'Eu fui para ele (=Siba) ficar alegre'

Como o tema verbal descritivo -uríwete 'ficar alegre' pertence à classe II, ele recebe o alomorfe /h-/. Temas da classe I, como por exemplo -katu 'ficar bom', recebem o alomorfe /i-l, também de não contigüidade, caso ocorram no mesmo contexto sintático que o tema -urì wete. O exemplo (19) ilustra a ocorrência do tema descritivo -katu.

\section{Tema da Classe I}

(19) a-ha i-katu po

1-ir REL -bom GER

'Eu fui para ele (=Siba) ficar bom'

Vimos que o gerúndio dos verbos transitivos, exemplos (1) a (14), estabelece correferencialidade do seu sujeito com o da oração anterior. Entretanto, o gerúndio dos verbos descritivos permite duas alternativas:

(i) correferência do seu sujeito com o sujeito da oração oração anterior, exemplos (15) e (16);

(ii) ausência de correferência com o sujeito da oração anterior, exemplos (17) a (19). 


\section{SEMELHANÇAS NA CODIFICAÇÃO DE O E $S_{o}$}

Nos exemplos (1) a (19), há um estreito paralelismo na maneira como o verbo transitivo e o verbo descritivo codificam os argumentos $\mathrm{O}$ e So. Conforme foi mostrado nas seções anteriores, $\mathrm{O}$ e So são referidos no verbo pelos mesmos marcadores: os prefixos relacionais. Diante deste paralelismo, nota-se que a codificação de $\mathrm{O}$ e So, nas orações de gerúndio analisadas até aqui, equivale ao que Dixon (1979) classifica como sendo um sistema ergativo.

Não obstante, o mesmo não se verifica no gerúndio dos verbos intransitivos. Como veremos adiante, a codificação de Sa é realizada por meio de uma outra série de marcadores, os prefixos pessoais nominativos.

\section{CONSTRUÇÕES COM VERBOS INTRANSITIVOS}

Estas construções envolvem verbos intransitivos que, na maioria dos casos, descrevem atos volicionais ou desejados: rir, assentar, trabalhar, entrar, andar, caminhar, etc., e certos processos corporais involuntários: dormir, tossir, espirrar, etc. (cf. Pontes, 1986:80). Antes de apresentarmos a codificação de Sa na língua Tembé, vejamos como a mesma se realiza na língua Tupinambá.

\subsection{Codificação de Sa na língua Tupinambá}

Na língua Tupinambá, a codificação de Sa se realiza por um inventário específico de prefixos que 'só desempenham a função subjetiva (= nominativa), e têm seu uso limitado ao gerúndio dos verbos intransitivos' (Rodrigues, 1953:125). Esses prefixos formam um paradigma à parte, se comparados com os prefixos relacionais usados para codificar $\mathrm{O} e$ So e com os prefixos nominativos usados para fazer referência ao sujeito dos verbos transitivos (A) e ao sujeito dos verbos intransitivos $\mathrm{Sa}$, nas orações principais. Os prefixos do Tupinambá são os seguintes:

Tabela I: Marcadores de pessoas exclusivos no gerúndio dos verbos intransitivos em Tupinambá

\begin{tabular}{|c|c|}
\hline pessoas & prefixos de gerúndio \\
\hline 1 singular & wi- \\
\hline 12 inclusivo & ya- \\
\hline 13 exclusivo & Oro- \\
\hline 2 singular & e- \\
\hline 23 plural & pe- \\
\hline 3 & o- \\
\hline
\end{tabular}


O exemplo (20) ilustra o paradigma de ocorrência dos prefixos de gerúndio no verbo intransitivo -puka 'rir'. Está implícito neste paradigma que o sujeito do gerúndio é correferente com o da oração principal.

(20) wi-puka-ßo 'para eu rir'

ya-puka-ßo 'para nós (inclusivo) rirmos'

oro-puka-ßo 'para nós (exclusivo) rirmos'

e-puka-ßo 'para você rir'

pe-puka-ßo 'para vocês rirem'

o-puka-ßo 'para ele(s) rir(em)'

Estes prefixos têm, assim, a função exclusiva de codificar Sa nas orações de gerúndio, à diferença dos prefixos relacionais que são usados para codificar $\mathrm{O}$ e So.

\subsection{Codificação de Sa na língua Tembé}

A língua Tembé, entretanto, diferencia-se da língua Tupinambá porque não faz uso de um inventário de prefixos pessoais exclusivos para o gerúndio dos verbos intransitivos. Ao contrário, os marcadores usados para codificar Sa são os prefixos pessoais nominativos, que também ocorrem nas orações principais . Estes prefixos são os seguintes:

$\begin{array}{ll}\text { a- } & \text { 'eu' } \\ r e- & \text { 'você' } \\ d a- & \text { 'nós INCL' } \\ u r u- & \text { 'nós EXCL' } \\ p e- & \text { 'vocês' } \\ u-\sim o-\sim w- & \text { 'ele(s) ou ela(s)' }\end{array}$

A ocorrência destes prefixos não é condicionada pelo critério de contigüidade, nem varia de acordo com as classes temáticas dos verbos, como se observou para os prefixos relacionais. O paradigma em (21) ilustra as ocorrências destes prefixos para codificar Sa na língua Tembé. Nestes exemplos, as orações de gerúndio apresentam o sujeito correferente ao da oração principal e são classificadas como gerúndio contemporâneo, já que exprimem uma ação simultânea a outra.

Gerúndio Contemporâneo

(21) a-ha a-sewpə 'Eu fui entrando'

re-ho re-sew pə 'Você foi entrando'

da-ha da-sew po 'Nós (inclusivo) fomos entrando'

oro-horu-sew po 'Nós (exclusivo) fomos entrando'

pe-ho pe-sew po 'Vocês foram entrando'

o-ho u-sew pa 'Ele(s) foi/foram entrando' 


\subsection{Correferência dos sujeitos}

Vimos que o gerúndio do verbo transitivo nas três línguas implica a correferência entre seu sujeito e o sujeito da oração principal. Esta condição se realiza também para o gerúndio dos verbos intransitivos na língua Tembé, conforme se observa nas orações (22) e (23b).

\section{$\underline{\text { Sujeitos Correferentes }}$}

Gerúndio Contemporâneo

$\begin{array}{llll}a_{i}-\text { ha avião pupe } & a_{i} \text {-sew } & \text { po } & \text { kurì. } \\ \text { 1-ir avião dentro de } 1 \text {-entrar } & \text { GER } & \text { RES } \\ \text { 'Eu fui entrando para dentro do avião então' } & \end{array}$

No entanto, assim como o gerúndio dos verbos descritivos, exemplos (17) a (19), o gerúndio dos verbos intransitivos permite ainda que o seu sujeito seja correferente, além de $\mathrm{A}$ e $\mathrm{Sa}$, com outros constituintes das orações precedentes, por exemplo o objeto $(\mathrm{O})$, sejam estas orações principais ou não.

$\mathrm{Na}$ oração em (24c), o sujeito (Sa) da oração de gerúndio, referido no verbo pelo prefixo $o$-, não é correferente com o sujeito (A), mas com objeto (O) $k a^{\prime} i$ 'macaco' da oração principal (24a). Além de ser correferente com o objeto da oração principal, observase que ele é ainda correferente com o sujeito (S) da oração temporal, embora ela não seja a principal.

\section{Gerúndio Contemporâneo}

(24a) $\mathrm{a}_{\mathrm{i}}$-esak $\quad \mathrm{ka}^{\prime} i_{j}$ 1 -ver macaco

$\begin{array}{lll}t_{j}-u r & \text { mehe } & w \text {-iko } \\ \text { REL-Vir } & \text { SUB } & 3 \text {-AUX }\end{array}$

$\begin{array}{lllll}o_{j} \text {-por } & \text { pə } & \text { he } & \varnothing \text {-kutìr } & \text { kurì. } \\ \text { 3-pular } & \text { GER } & 1 & \text { REL-em direção a } & \text { RES }\end{array}$

'Eu vi o macaco, quando ele estava vindo, pulando na minha direção'

No exemplo abaixo, outra situação sintática é verificada. Desta vez, o sujeito (Sa) do gerúndio aditivo é correferente com o objeto $(\mathrm{O})$, expresso pelo sintagma tenetehara, da oração (25b), e não com o sujeito Pedro da oração (25a). 


\section{Gerúndio Aditivo}

\begin{tabular}{|c|c|c|c|c|c|}
\hline (25a) & $\begin{array}{l}\text { Pedro }_{j} \\
\text { Pedro }\end{array}$ & $\begin{array}{l}u_{j} \text {-sew } \\
3 \text {-entrar }\end{array}$ & $\begin{array}{l}o_{j}^{-}-h o \\
\text { 3-ir }\end{array}$ & $\begin{array}{l}t \dot{x} p \dot{\dot{x}} d \\
\text { casa }\end{array}$ & $\begin{array}{l}\text { pupe } \\
\text { dentro de }\end{array}$ \\
\hline$(25 b)$ & $\begin{array}{l}w_{j} \text {-esak } \\
\text { 3-ver }\end{array}$ & $\begin{array}{l}\text { tenetehara }_{i} \\
\text { tenetehara }\end{array}$ & & & \\
\hline$(25 c)$ & $\begin{array}{l}u_{i} \text {-dimuり主ta } \\
\text { 3-conversar }\end{array}$ & $\begin{array}{l}p ə \\
\text { GER }\end{array}$ & & $\begin{array}{l}w \partial . \\
\text { PL }\end{array}$ & \\
\hline
\end{tabular}

O último exemplo que se segue contrasta com os dois acima por permitir que a correferência desta vez ocorra com o objeto 主wìra 'pau' da oração subordinada temporal (26a).

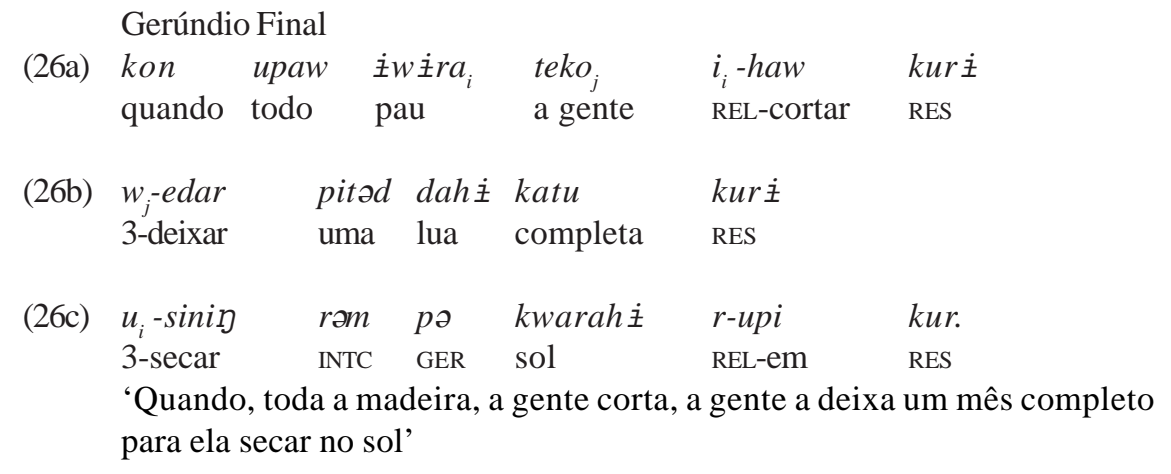

Vê-se, então, que o sujeito do verbo intransitivo, nas orações de gerúndio, pode ser correferente não só com o sujeito mas também com o objeto da oração anterior, seja esta principal ou subordinada. A correferência de Sa com constituintes de orações anteriores parece depender de qual está em foco no contexto.

\section{CONCLUSÃO}

Com base nos dados analisados nas seções anteriores, pode-se constatar uma diferença na maneira como os diferentes gerúndios operam a correferencialidade com os elementos sintáticos das orações que os antecedem. Enquanto o gerúndio dos verbos intransitivos indica a correferencialidade com o sujeito ou com o objeto da oração anterior, conforme exemplos (24) a (26), seja esta principal ou não, o gerúndio dos verbos transitivos só a indica com o sujeito, A ou Sa, da oração anterior, conforme os exemplos (1) a (19).

Além disto, as orações de gerúndio operam com um sistema cindido: um em que se codifica So e O por meio dos prefixos relacionais, constituindo-se um sistema ergativo, e outro em que se codifica Sa por meio dos prefixos pessoais nominativos. Observa-se também que a função A não é marcada nas orações de gerúndio. A tabela II abaixo resume os dois sistemas de codificação dos argumentos. 
A tabela II: sistema de marcação cindida nas orações de gerúndio da Língua Tembé

\begin{tabular}{|c|c|c|}
\hline & \multicolumn{2}{|c|}{ tipos de marcadores } \\
\hline funções sintáticas & $\begin{array}{c}\text { prefixos pessoais } \\
\text { nominativos }\end{array}$ & prefixos relacionais \\
\hline $\mathrm{O} / \mathrm{So}$ & - & + \\
\hline $\mathrm{Sa}$ & + & - \\
\hline
\end{tabular}

\section{ABREVIATURASUSADAS}

$\begin{array}{ll}\text { AUX } & \text { Verbo auxiliar } \\ \text { DUB } & \text { Dubitativo } \\ \text { CAUS } & \text { Causativo } \\ \text { ENF } & \text { Enfase } \\ \text { EXCL } & \text { Exclusivo } \\ \text { FUT } & \text { Partícula que indica tempo futuro } \\ \text { GER } & \text { Partícula que indica o gerúndio } \\ \text { INCL } & \text { Inclusivo } \\ \text { INT } & \text { Sufixo de intensidade } \\ \text { INTC } & \text { Intencional } \\ \text { PASS } & \text { Tempo passado } \\ \text { PL } & \text { Plural } \\ \text { PROG } & \text { Aspecto progressivo } \\ \text { REL } & \text { Prefixo relacional } \\ \text { RES } & \text { Resultativo } \\ \text { SUB } & \text { Partícula de subordinação } \\ \text { A } & \text { Sujeito de verbo transitivo } \\ \text { O } & \text { Objeto de verbo transitivo } \\ \text { S } & \text { Sujeito de verbo intransitivo e descritivo no sistema ergativo } \\ \text { So } & \text { Sujeito de verbo descritivo } \\ \text { Sa } & \text { Sujeito de verbo intransitivo } \\ 1 & \text { Primeira pessoa, 'eu' } \\ 2 & \text { Segunda pessoa, 'você' } \\ 12 & \text { Primeira pessoa inclusiva, nós } \\ 13 & \text { Primeira pessoa exclusiva, nós } \\ 32 & \text { Segunda pessoa plural, 'vocês' } \\ 3 & \text { 'ele(s) ou ela(s)' } \\ & \end{array}$

\section{REFERÊNCIAS BIBLIOGRÁFICAS}

BENDOR-SAMUEL, D. (1972) Hierarchical Structures in Guajajara. Norman: Summer Institute of Linguistics, University of Oklahoma. 
Boudin, Max H. (1966) Dicionário de Tupi Moderno. Faculdade de Filosofia, Ciências e Letras de Presidente Prudente, São Paulo.

COMRIE, Bernard. (1981) Language Universals and Linguistic Typology (Syntax and Morphology). University of Chicago Press

DIXON, R. M. W. (1979) Ergativity, Lg. 55:59-138.

HARRISON, Carl. (1986) Verb Prominence, Verb Initialness, Ergativity and TypologicalDisharmony in Guajajara. Handbook of Amazonian Languages, VOl. 1. Edited By Derbyshire and Pullum, 407-439. Berlin: Mouton de Gruyter.

JENSEN, Cheryl. (1990) Cross-Referencing Changes in Some Tupí-Guaraní Languages. In: D.L.Payne (ed.). Amazonian Linguistics: Studies in Lowland South American Languages. Austin: University of Texas Press.

PONTES, Eunice Souza de Lima. (1986) Sujeito da Sintaxe ao Discurso. São Paulo, Editora Ática: Série Ensaios 125

RICARDO, Carlos Alberto. (Coordenador Geral) (1985). Povos Indígenas no Brasil. São Paulo: CEDI (Centro Ecumênico de documentação e Informação).

RICE, Frederick John Duval. (1934) O Idioma Tembé (Tupi-Guarany). Journal de la Société des Américanistes, N. S., Paris (26): 109-180.

RODRIGUES, A. D. (1953) Morfologia do Verbo Tupi. Letras 1:121-152. Curitiba. .(1981). Estrutura do Tupinambá. MS.

.(1984/1985). Relações Internas na Família Lingüística Tupí-Guaraní. Revista de Antropologia 27/28:33-53. São Paulo: USP.

(1986). Línguas Brasileiras: Para o Conhecimento das Línguas Indígenas. Ed. Loyola. São Paulo

.(1990). You and I = Neither You Nor I: The Personal System of Tupinambá. In: D.L.Payne (ed.). Amazonian Linguistics: Studies in Lowland South American Languages. Austin: University of Texas Press.

SEKI, Lucy. (1990) Kamaiurá (Tupí-Guaraní) as an Active-Stative Language. In:D.L.Payne (ed.). Amazonian Linguistics: Studies in Lowland South American Languages. Austin: University of Texas Press.

SHOPEN, Timothy. (1986) Language Typology and Syntatic Description. Cambridge University Press, 3 vols.

SILVA, Norval O. Da. (1993) Esboço de Gramática Pedagógica da Língua Tembé. SIL, MS. 